\title{
If the statistics underlying macroscopic and microscopic (quantum scale) events were to fundamentally differ would this affect the biology of cancer?
}

\author{
Anderson $\mathrm{KM}^{1 *}$ and Patel $\mathrm{MK}^{2}$ \\ ${ }^{1}$ Professor Emeritus, Rush Medical College, USA \\ ${ }^{2}$ University of Illinois College of Nursing, USA
}

In our "macroscopic" world it is a truism that an action is often followed by an equal and opposite reaction. In the "microscopic" realms (chemical, biological, quantum environments), that response often is mimicked. For example, stressed cancer cells can exhibit enhanced resistance to therapy and development of alternate genetic/epigenetic responses that increase proliferation and developmental / proliferative events unanticipated by the physician. These considerations provide a background for considering these and other possible consequences to hypoxia or other cellular stresses by deterministic, or by random, stochastic cancer cell responses to stresses. According to some, random refers to a variable, stochastic to a process or system.

A stochastic process can be defined as a process that over time undergoes one or more "chance" events. They can either be deterministic (the next event can be calculated with certainty), or random, (the next event is completely "free" without predictable properties). A "deterministic chaotic" system does have predictable properties but they may be impossible to identify. It seems to be the case that stochastic events can be studied by several different categories of quantum statistics including Fermi Dirac and Bose Einstein statistical programs. Presumably each stochastic event has an overall probability, depending upon its' prior state, contingent upon it's' "history". The variance and mean of a true stochastic event should be equal, characteristic of a Poisson distribution. Stochastic circuits capable of fairly reproducible behavior have been designed. (References are available in [1].

The effects of unidentified potential stochastic events on biological processes are obviously unknowable unless their effects subsequently can be identified. We considered some of these implications employing a differential logistic Monte Carlo simulation with continued stochastic input to a fixed carrying capacity, $\mathrm{K}$, of slowly or rapidly proliferation daughter "cancer" cells as an initial model for this discussion [1]. This model can representationally mimic opportunities for these stochastic effects on cancer or nonmalignant cells contributing to their mosaicism. We imagine the interactions of multiple cellular biochemical pathways subject to random genetic/epigenetic events as resembling "sum-over-paths" or "sum- over- histories" [2,3], with an ability to reinforce, cancel or leave unchanged specific interactions as cells adapt to the vagaries of responding to random events.

Human cultured PC-3 prostate cancer cells can provide a somewhat dated example [4]. Cells positive for CD 44 / CD 41 antigens are believed to include prostate stem cells. When cultured under nitrogen for 48 hours, the percentages, absolute and relative numbers of doubly- labelled (DL) cells were higher than values for normoxic controls The final $\mathrm{pH}$ of the hypoxic medium was a more alkaline 7.8, but if cells were cultured with $95 \%$ nitrogen / $5 \%$ carbon dioxide or in ambient atmosphere with $5 \%$ carbon dioxide to maintain a more acidic 7.2$7.4 \mathrm{pH}$ environment, the values for (DL) hypoxic and normoxic cell values were nearly comparable. One can tentatively suggest that under these culture conditions, an increase in medium alkalinity increased the numbers and expression of "stem" cells expressing these DL antigens; i.e. hypoxia under these conditions augmented stem cell survival, proliferation and antigen expression. Any selective growth or survival advantage to putative hypoxic stem cells should provide increased opportunity for genetic / epigenetic changes. Hypoxic cells are considered to be more susceptible to genetic changes than cells cultured under more physiological conditions [5]. Much more penetrating analyses of this problem should be available with the ability to untangle subcellular biochemical events from analysis of DNA and RNA sequence and functional studies and identification of "nodes" and their functional interconnections. Application of artificial intelligence to such analyses is already under way $[6,7]$.

Ruminations of this sort lead almost inevitably to one of the many hierarchical "classifications" of genomic complexity subject to random events [8]. Level 1 events affecting modulation of basic survival requirements, as DNA replication, metabolic energy etc. Level 2 events including more complex random "tactical" changes affected higher level networks and nodes necessary for regulating cellular survival. Level 3 "strategic" events directing fundamental modification of fundamental survival, deletion or gain of chromosomal material, programs directing differentiation, reprogramming of cellular evolution and the like. Lastly a hypothetical Level 4, of "chaotic randomness", contributing to fundamental modifications such as the formation of new species, and genera, modification of bilateral symmetry, dorsal ventral or anteroposterior differences etc. It is not clear that most cancers express such radical reorganizations.

In closing, several questions occur. Does the logic and the role of chance in macro and micro (quantum) systems differ in ways that can be detected? If so, how might biology (and most other disciplines) be

${ }^{\star}$ Correspondence to: Anderson KM, 427 Ridge Ave., Evanston, Ill 60202, USA, E-mail: kanderso427@sbcglobal.net

Received: May 15, 2019; Accepted: June 05, 2019; Published: June 10, 2019 
Anderson KM (2019) If the statistics underlying macroscopic and microscopic (quantum scale) events were to fundamentally differ would this affect the biology of cancer?

affected by differences in the initiation, frequency and implementation or emergence of stochastic events at the two levels of abstraction? In point of fact, do these questions make much sense at all or do they represent a non-sense?

\section{References}

1. Anderson KM, Rubenstein, M, Guinon, P, Patel MK (2015) Oncogenic mutational / epigenetic events: Deterministic, stochastic or random: Implications for hypoxic cancer cells and tumor heterogeneity. Integ Can Sci Ther 2: 61-65.

2. Feynman RP (1963) Six easy pieces. Basic Books, NY.

3. The Feynman lectures on physics $\left(3^{\text {rd }} \mathrm{Vol}\right)$. RB Leighton and M Sands.
4. Anderson KM, Guinan P, Rubenstein M (2011) The effect of normoxia and hypoxia on a prostate (PC-3) CD44/CD41 cell side fraction. Anticancer Res 31: 487-494. [Crossref]

5. Mihhaylova VT, Bindra RS, Yuan J, Campisi D, Narayanan L, et al. (2003) Decreased expression of the DNA mismatch repair gene MLH1 under hypoxic in mammalian cells. Mol cell biol 32: 3265-3273. [Crossref]

6. Zoheir E (2006) Applications of artificial intelligence in bioinformatics: A review. Expt Sys with Apps 30: 2-10

7. Li H, Lu L, Manly KF, Chesler EJ, Bao L, et al. (2005) Inferring gene transcriptional modulatory relations: a genetical genomics approach. Hum Mol Genet 14: 1119-1125. [Crossref]

8. Anderson KM, Patek MK (2018) Cancer as an Emergent Phenomenon. J Can Res Ther Oncol 6: 1-9.

Copyright: $\odot 2019$ Anderson KM. This is an open-access article distributed under the terms of the Creative Commons Attribution License, which permits unrestricted use, distribution, and reproduction in any medium, provided the original author and source are credited. 